\title{
1 Seasonal dynamics of zooplankton nutrient recycling in a hypereutrophic reservoir
}

2 Tyler J. Butts ${ }^{1,3^{*}}$, Eric K. Moody ${ }^{2}$, Grace M. Wilkinson ${ }^{1,3}$

$3{ }^{1}$ Ecology, Evolution and Organismal Biology Department, Iowa State University, Ames, IA

$4 \quad{ }^{2}$ Department of Biology, Middlebury College, Middlebury, VT

$5 \quad{ }^{3}$ Current Address: Center for Limnology, University of Wisconsin - Madison, Madison, WI

7 *Corresponding Author:

8 Tyler Butts

9 tibutts@wisc.edu

10 Key Words: nutrient cycling, stoichiometry, hypereutrophic, body size, excretion

12 This manuscript is to be submitted for publication in the Journal of Plankton Research. Please

13 note that this manuscript has not yet undergone peer-review nor been formally accepted for

14 publication. As new versions of this manuscript are generated, this document will be updated and

15 may have slight differences in content. If accepted, the final version of the manuscript will be

16 available via the 'peer-reviewed publication DOI' link on the right-hand side of this webpage.

17 Please feel free to contact the corresponding author. 
ABSTRACT

Consumer-driven nutrient cycling influences aquatic ecosystem functioning by altering energy flow as well as the movement and transformation of nutrients. In hypereutrophic lakes,

22 zooplankton nutrient recycling has largely been considered negligible due to the high

23 concentrations of available nutrients. A recent comparative analysis found that zooplankton

24 community composition may influence nutrient availability, particularly phosphorus availability,

25 in hypereutrophic lakes. However, the magnitude and timing of the effect of zooplankton

26 nutrient recycling and grazing on phytoplankton in hypereutrophic lakes remains unclear. We

27 quantified zooplankton, phytoplankton, and nutrient concentration dynamics during the summer

28 of 2019 in a temperate, hypereutrophic reservoir. We found that zooplankton excretion

29 contributed a substantial proportion (23-46\%) to the inorganic phosphorus (P) pool in early

30 summer when P concentrations were low and limiting phytoplankton growth. Zooplankton

31 excretion of $\mathrm{P}$ also significantly $(p=0.003)$ contributed to variation in phytoplankton community

32 composition in early summer. Further, we found evidence that zooplankton affected

33 phytoplankton size distributions through selective grazing of smaller phytoplankton cells.

34 Overall, our results demonstrate the important role of zooplankton in hypereutrophic lakes as

35 excretion helped drive springtime phytoplankton dynamics through nutrient recycling while

36 grazing influenced phytoplankton size distributions later in the summer. 
INTRODUCTION

Animal consumers drive nutrient cycling in aquatic ecosystems by controlling the movement and transformation of nutrients over time and across space (Atkinson et al., 2017). Aquatic consumers such as zooplankton ingest primary producers then excrete and egest metabolized and unassimilated materials as waste, recycling nutrients back into the ecosystem (Vanni, 2002). In turn, these excreted, recycled nutrients can be taken up by phytoplankton to produce new biomass (Sarnelle and Knapp, 2005). Mismatches between consumer demand for and assimilation efficiency of elements and the elemental composition of primary producers drives the stoichiometry of nutrients recycled back into the ecosystem (Elser and Hassett, 1994; Sterner, 1990). Elemental mismatches can then lead to greater nutrient recycling of a particular element that may result in changes to ecosystem nutrient limitation and alter trophic interactions between consumers and their resource (Elser et al., 2000; Dobberfuhl and Elser, 2000).

The community composition of both phytoplankton and zooplankton can influence the stoichiometry of recycled nutrients and generate strong differences in nitrogen $(\mathrm{N})$ and phosphorus (P) recycling (Balseiro et al., 1997). For example, copepods and small cladocerans generally retain more N whereas Daphnia generally retain more P (Elser and Urabe, 1999). Differences in $\mathrm{N}$ and $\mathrm{P}$ retention between zooplankton taxa can result in copepod and small cladoceran dominated communities retaining more $\mathrm{N}$ and recycling more $\mathrm{P}$ into the water column, thereby driving phytoplankton to N-limitation (Elser et al., 2000, 1988). Phytoplankton community composition varies with lake trophic state and nutrient limitation as different phytoplankton genera prefer different nutrient forms (Andersen et al., 2020). Cyanobacteriadominated phytoplankton communities, which often arise in nutrient enriched ecosystems, are uniquely resistant to zooplankton grazing due to the ability of many genera to form colonies or

60 filaments, as well as their poor nutritional quality, toxin production and rapid growth rates

61 (Moustaka-gouni and Sommer, 2020). This results in a loss of nutrient and energy transfer to

62 higher trophic levels due to poor assimilation efficiency (Karpowicz et al., 2021, 2020). In

63 combination, zooplankton-phytoplankton interactions affect nutrient recycling in aquatic

64 ecosystems; however, the effects may vary depending on the severity of nutrient enrichment.

65 Much of our understanding regarding zooplankton nutrient recycling comes from 66 oligotrophic and eutrophic ecosystems (Elser et al., 2000; Moegenburg and Vanni, 1991), though many temperate lakes are increasingly becoming hypereutrophic due to continued land use 
conversion and climate change (Stoddard et al., 2016). The extremely high nutrient

69 concentrations in hypereutrophic lakes can produce unique conditions compared to less enriched waterbodies such as large seasonal variability in nutrient limitation of phytoplankton growth (Andersen et al., 2020), substantial internal phosphorus loading under oxic conditions (Song and

72 Burgin, 2017), and a more complex mix of top-down and bottom-up forces affecting

73 phytoplankton communities (Matsuzaki et al., 2018). However, the contribution of zooplankton

74 nutrient recycling in hypereutrophic ecosystems is often considered negligible as high

75 concentrations of inorganic nutrients within the water column can dampen the influence of nutrient inputs from consumer excretion (Spooner et al., 2013). Despite this, zooplankton may still influence nutrient availability in hypereutrophic lakes as nutrient limitation and zooplankton biomass shift throughout the growing season. Additionally, selective feeding on small phytoplankton by small-bodied zooplankton increases the dominance of large phytoplankton species, including filamentous and colonial cyanobacteria (Erdoğan et al., 2021). This may influence nutrient availability as cyanobacteria have the capacity for luxury nutrient uptake, subsequent storage of excess nutrients, and the ability to use $\mathrm{N}$ forms inaccessible to other

83 phytoplankton species, such as diazotrophs that can fix atmospheric nitrogen (Cottingham et al.,

84 2015). As hypereutrophic lakes are dominated by smaller-bodied zooplankton including microzooplankton and ciliates, selective grazing pressure on the phytoplankton community may indirectly influence nutrient availability.

A recent analysis of mesozooplankton (i.e., copepods, cladocerans, and rotifers; hereafter zooplankton) stoichiometric traits found that the community $\mathrm{N}: \mathrm{P}$ ratio shifted towards N-rich species with increasing eutrophication (Moody and Wilkinson, 2019). As such, in hypereutrophic lakes, zooplankton may be increasing $\mathrm{P}$ recycling. This hypothesis was supported by the fact that

91 the seston $\mathrm{N}: \mathrm{P}$ in hypereutrophic lakes was lower compared to less enriched lakes concurrent

92 with more N-rich zooplankton communities that exhibit greater P recycling. This analysis

93 suggests that the unique functioning of hypereutrophic lakes, even compared to eutrophic lakes, 94 was due in part to the consumers inhabiting them. However, this was a comparative study among 95 lakes based on a single sampling point in summer. It is well established that zooplankton and 96 phytoplankton communities are dynamic and undergo an annual succession over the course of a 97 summer growing season, which can vary depending on lake trophic state and other variables 98 (Sommer et al., 2012). Furthermore, the balance of top-down and bottom-up forces in lakes 
99 varies with nutrient ratios and concentrations across a season (Rogers et al., 2020). In the scope

100 of this comparative study (Moody and Wilkinson, 2019), the seasonal variability within

101 zooplankton, phytoplankton, and nutrient dynamics was not captured. As such, it remains unclear

102 how hypereutrophic lakes are influenced by zooplankton nutrient recycling throughout the

103 summer growing season.

104 We investigated the role of zooplankton nutrient recycling in a hypereutrophic waterbody

105 by quantifying zooplankton, phytoplankton, and water column nutrient dynamics across the

106 summer growing season. We used effect traits, which directly link individual activity to

107 ecosystem processes (Hébert et al., 2017, 2016b), to estimate storage and flux of nutrients driven

108 by zooplankton consumers. Effect traits like size (Litchman et al., 2013) or elemental

109 composition (Sterner and Elser, 2002) can be used to assess nutrient cycling by quantifying

110 zooplankton body stoichiometry and excretion rate, as well as to infer growth and predation

111 based on community body size structure. With this approach we asked: (1) do zooplankton in

112 hypereutrophic lakes alter P availability, and how does that vary over the course of a summer

113 growing season? And (2) do zooplankton contribute to variation in phytoplankton community

114 composition amidst other environmental variables? We hypothesized that zooplankton nutrient

115 recycling would contribute to $\mathrm{P}$ availability before the onset of high internal $\mathrm{P}$ loading in

116 midsummer. Furthermore, we expected zooplankton excretion would contribute to variation in

117 phytoplankton community composition due to body stoichiometry shifting nutrient availability.

118 Finally, we hypothesized that zooplankton grazing would affect phytoplankton size structure

119 throughout the summer due to selective grazing on smaller phytoplankton.

\section{METHODS}

\section{Study Lake}

123 Green Valley Lake $\left(46^{\circ} 06^{\prime} 02^{\prime \prime} \mathrm{N}, 9^{\circ} 23^{\prime} 05^{\prime \prime} \mathrm{W}\right)$ is a hypereutrophic reservoir built in 1952 as an

124 impoundment of the Platte River in southwestern Iowa (USA). The maximum depth is $7.3 \mathrm{~m}$,

125 with an average depth of $3.2 \mathrm{~m}$ and a surface area of 156 ha. The fish community is dominated

126 by crappie (Pomoxis spp.), bluegill (Lepomis macrochirus), and largemouth bass (Micropterus

127 salmoides). Additionally, there is a small population of common carp (Cyprinus carpio) and

128 channel catfish (Ictalurus punctatus). The watershed is dominated by row crop agriculture

129 (68.4\% corn/soybean rotation). Consequently, Green Valley Lake is enriched with nutrients and 
130 beset by annual phytoplankton blooms dominated by cyanobacteria (Supplementary Figure S1).

131 To characterize zooplankton nutrient recycling in Green Valley Lake, zooplankton,

132 phytoplankton, and water samples for nutrient analysis were taken weekly at the deepest point in

133 the reservoir during the summer of 2019. Samples were taken from early May (day of year; DOY

134 143) to early September (DOY 251). An additional sampling event occurred on DOY 273, but

135 only zooplankton and nutrient samples were collected at that time. Additionally, a YSI EXO3

136 sonde (Yellow Springs Instruments, Yellow Springs, Ohio, USA) was deployed at $0.5 \mathrm{~m}$ at the

137 deepest point in the reservoir and collected temperature, total dissolved solids, and $\mathrm{pH}$

138 measurements every 15 minutes. Daily averages of each variable were used in our analyses.

139

140 Plankton Analysis

141 Zooplankton and phytoplankton biomass and community composition were quantified for

142 each sampling event during the summer growing season. Zooplankton were sampled via a

143 vertical tow of a Wisconsin net (63 $\mu \mathrm{m}$ mesh) from $6 \mathrm{~m}$ depth. Samples were preserved with a

144 formaldehyde solution (5\% concentration after sample addition) in the field and later transferred

145 to $70 \%$ ethanol. Phytoplankton samples were a composite sample over depth. Water was

146 collected in a $4 \mathrm{~L}$ Van Dorn sampler from 0.25, 1, 2, 3, and $4 \mathrm{~m}$ depths, then mixed in a $20 \mathrm{~L}$

147 carboy in the field. Samples were taken to $4 \mathrm{~m}$ depth which was the average thermocline depth at

148 the sampling point $(4.0 \pm 1.23 \mathrm{~m}$; s.d. $)$. A $1 \mathrm{~L}$ sample was then taken from the carboy following

149 thorough mixing and preserved with Lugol's solution in the field.

150 Zooplankton samples were identified and enumerated with a Leica MZ8

151 stereomicroscope connected to Motic Images software. For each sample a $1 \mathrm{~mL}$ subsample was

152 taken where a minimum of 60 individual zooplankton were identified and enumerated. If less

153 than 60 organisms were in the subsample a second $1 \mathrm{~mL}$ subsample was counted. Individuals

154 were identified to genus for cladocerans and rotifers, order for copepods, and class for ostracods.

155 Copepod nauplii could not be identified to order and were simply identified as nauplii. We

156 measured zooplankton lengths to calculate dry mass per liter using length-weight regressions

157 (Dumont et al., 1975; McCauley, 1984). For visual display of the zooplankton data, they were

158 separated into nine taxonomic groups: Daphnia, Simocephalus, Ceriodaphnia, Bosmina,

159 Chydorus, rotifers, calanoids, cyclopoids, nauplii, and ostracods (Supplementary Table S1). 
Simocephalus contributed only $7 \%$ of total community biomass at its peak biomass and so were grouped with Daphnia for later analyses.

The $1 \mathrm{~L}$ phytoplankton samples were transferred to a graduated cylinder and allowed to settle in a dark environment for 8 days before the supernatant was removed with a vacuum

164 pump, leaving $50 \mathrm{~mL}$ of concentrated sample. A subsample was then removed from the concentrated sample and identified and enumerated using a modified Palmer-Maloney chamber. Phytoplankton were identified to genus and measured using a calibrated ocular reticle on a Leitz DM IL inverted microscope at 400x magnification. A minimum of 300 natural units across 8 fields were measured for each sample. Biovolume per liter was calculated based on phytoplankton shape and then converted to wet biomass per liter assuming a 1:1 ratio between wet mass and biovolume (Hillebrand et al., 1999; Sournia, 1978). Like zooplankton, phytoplankton genera were separated into six groups for visual display: bacillariophytes,

172 chlorophytes, chryso- and cryptophytes, Aphanothece, Microcystis, and other cyanophytes

173 (Supplementary Table S2). Both Aphanothece and Microcystis were the dominant genera of cyanobacteria, contributing the majority of phytoplankton biomass ( $88 \pm 18 \%$; s.d.) and therefore

175 were visualized separately.

\section{Nutrient Analysis}

178 To quantify the concentration and forms of nutrients in Green Valley Lake, surface water samples were collected at a depth of $0.25 \mathrm{~m}$ at the deep point. A subset of the water was first

180 filtered through Whatman glass fiber filters (pore size $=0.45 \mu \mathrm{m}$ ) in the field, preserved with concentrated sulfuric acid to a $\mathrm{pH}$ of 2 , and stored at $4{ }^{\circ} \mathrm{C}$ until analysis for soluble reactive

182 phosphorus (SRP) and nitrate + nitrite (NOx). Unfiltered sample water was preserved with 183 concentrated sulfuric acid to a $\mathrm{pH}$ of 2 and stored at $4{ }^{\circ} \mathrm{C}$ until analysis for total phosphorus (TP)

184 and total nitrogen (TN). The ascorbic acid method was used to quantify P concentrations with 185 filtered water for SRP and unfiltered water that had undergone persulfate digestion for TP. 186 Second-derivative ultraviolet spectroscopy was used to quantify NOx concentrations in filtered 187 samples and TN concentrations following persulfate digestion. $\mathrm{N}$ species were analyzed using an 188 Agilent Cary 8454 UV-VIS spectrophotometer (Agilent Technologies Inc, Santa Clara, CA, 189 USA) and P species were analyzed using a Seal Analytical AQ2 Discrete Analyzer (Seal 
Analytical Inc. Mequon, WI, USA). For data analysis, nutrient concentrations below detection were replaced with the instrument long-term method detection limit.

To investigate zooplankton nutrient recycling between different nutrient pools we quantified

193 the available concentrations of nitrogen $(\mathrm{N})$ and phosphorus $(\mathrm{P})$ as well as calculated total and

194 inorganic $\mathrm{N}$ and $\mathrm{P}$. Nutrient limitation of phytoplankton was determined by the N:P ratio of total

$195 \mathrm{~N}$ and P with N:P > 20 indicating P limitation (Guildford and Hecky, 2000). A decade of

196 summertime measurements of NHx in Green Valley Lakes indicates that it is rarely detectable

197 (Supplementary Material).

\section{Zooplankton Stoichiometry and Excretion}

To assess the contribution of zooplankton to nutrient availability we determined zooplankton elemental composition, nutrient storage, and excretion rate. We estimated elemental

202 composition and total nutrient storage by zooplankton $\left(\mathrm{L}^{-1} \mathrm{~d}-{ }^{1}\right)$ following methods described 203 previously (Moody and Wilkinson, 2019). Briefly, taxa-specific \% $\mathrm{N}$ and \% $\mathrm{P}$ collected from the 204 literature (Hamre, 2016; Hébert et al., 2016a; Hessen et al., 2007) were used to estimate total nutrient storage by multiplying $\% \mathrm{~N}$ and $\% \mathrm{P}$ by the biomass of each taxa and summing across the community on each sampling date. Although we are using trait data from largely oligotrophic lakes, zooplankton express fairly strong stoichiometric homeostasis (Persson et al., 2010) as well as low intraspecific stoichiometric variation between lakes (Prater et al., 2017) and variable food quality (Teurlincx et al., 2017). Thus, it is unlikely that intraspecific variation in $\% \mathrm{~N}$ and $\% \mathrm{P}$ values in our study lake will have a large influence.

212 equations (Supplementary Material). The equations relate zooplankton body size to $\mathrm{N}$ and $\mathrm{P}$

213 excretion rates derived from a compiled dataset of marine and freshwater zooplankton species

214 (Hébert et al., 2016b, 2016a). Briefly, for each sampling event we input the average dry mass per 215 zooplankton taxon into the allometric equations to determine individual $\mathrm{N}$ and $\mathrm{P}$ excretion rates $216\left(\mu \mathrm{M} \mathrm{N}\right.$ or $\mathrm{P}$ individual ${ }^{-1}$ hour $\left.^{-1}\right)$ then converted the hourly excretion rate to a daily rate $\left(\right.$ day $\left.^{-1}\right)$.

217 Next, we multiplied the daily excretion rates by the density of each taxon (individuals $\mathrm{L}^{-1}$ ), then 218 summed the excretion rates across taxa to calculate a zooplankton community excretion on that 219 sampling date $\left(\mu \mathrm{M} \mathrm{N}\right.$ or $\mathrm{P}$ day $\left.^{-1}\right)$. We calculated uncertainty in the excretion estimates by 220 propagating the variation in the slope and intercept from the allometric equations presented in 
221 Hébert et al., (2016b). We also calculated zooplankton excretion using other published

222 allometric equations from Wen and Peters (1994) that were derived from different underlying

223 datasets. The overall pattern of zooplankton excretion did not differ between the two methods;

224 however, the Wen and Peters (1994) based estimates of excretion were slightly higher

225 (Supplementary Table S3). We chose to use the more conservative estimate of zooplankton

226 excretion rates based on Herbert et al. (2016) in our analysis as the method also allowed us to

227 estimate uncertainty.

228

229

Data Analysis

To assess the magnitude of zooplankton $\mathrm{N}$ and $\mathrm{P}$ excretion in Green Valley Lake we compared the estimated concentration of excreted $\mathrm{N}$ and $\mathrm{P}$ over the course of a day to the measured surface water concentrations of inorganic $\mathrm{N}$ and $\mathrm{P}$ for each sampling event. This was 233 expressed as a percent of the inorganic nutrient pool:

$$
\left(\frac{\mu M N \text { or } P \text { excreted by zooplankton community in a day }}{\mu M \text { of inorganic } N \text { or } P \text { present in the surface waters }}\right) * 100
$$

To assess how zooplankton affected the rate of nutrient cycling over the course of the growing season we calculated the zooplankton nutrient turnover time of the inorganic $\mathrm{P}$ pool.

237 Turnover, in this case, is the number of days it would take for zooplankton excretion of $\mathrm{P}$, 238 estimated for a specific sampling date to reach the concentration SRP measured on the same 239 sampling date, assuming no uptake from phytoplankton (SRP/excretion rate). The turnover time 240 varies depending on the rate of zooplankton excretion and concentration of SRP in the surface 241 waters. We did not have a weekly measurement of ammonium as it was likely undetectable 242 based on previous monitoring, so we could not calculate turnover of the soluble N pool. Short 243 turnover times of inorganic $\mathrm{P}$ indicate zooplankton are significantly contributing to the inorganic

244 P pool in Green Valley Lake. Long nutrient turnover times indicate factors other than 245 zooplankton excretion are driving nutrient availability.

246 To assess the drivers of phytoplankton community composition across the growing season 247 we performed a distance based-redundancy analysis (db-RDA). In order to ascertain whether 248 zooplankton nutrient recycling partially explained phytoplankton community composition we 249 included zooplankton excretion and body stoichiometry with other potentially important 
environmental variables including inorganic nutrient concentration (Filstrup and Downing,

251 2017), temperature (Striebel et al., 2016), pH (Rönicke et al., 2010), and total dissolved solids

252 (Ahmed and Wanganeo, 2015). Phytoplankton species biomass data were Hellinger transformed

253 and species that only occurred once in the full summer dataset and contributed $<1 \%$ of total

254 biomass were removed to decrease the weight of rare species. Environmental variables were z-

255 scored in order to correct for differences in scale and magnitude (Legendre and Legendre, 1998).

256 The db-RDA was performed using a Bray-Curtis distance matrix using the square roots of

257 dissimilarities to avoid negative eigenvalues (Legendre and Anderson, 1999). Missing or lost

258 samples were removed from the final analysis. The best model was determined using forward

259 and backward stepwise regression with model significance determined using a Monte Carlo

260 permutation test (999 permutations, $p$-value $<0.05$ ).

261 To investigate the importance of zooplankton top-down control we calculated the

262 percentage of zooplankton biomass to phytoplankton biomass. The percentage of zooplankton

263 biomass in comparison to phytoplankton biomass has been used as a proxy for describing the

264 importance of top-down v. bottom-up control in lakes, with a high percentage ( 40-50\%)

265 indicating strong top-down control and a low percentage $(\sim 10 \%)$ indicating weak top-down

266 control (Leroux and Loreau, 2015; Havens and Beaver, 2013). Additionally, we compared the

267 size distributions of zooplankton and phytoplankton communities and individual zooplankton

268 mass, as well as their changes over time. Zooplankton length data were compiled for up to 25

269 individuals per taxa per sampling date then used to estimate body mass with taxa-specific length-

270 weight regressions (Dumont et al., 1975; McCauley, 1984). When more than 25 individuals of a

271 species were present in a sample, the total number was counted, but length was only measured

272 for the first 25 individuals. The greatest axial linear dimension (GALD) of phytoplankton was

273 measured as the greatest distance across an individual cell, colony, or filament (i.e., natural unit),

274 such as would be encountered by a zooplankton grazer. Distributions of zooplankton length and

275 body mass were compared to the distribution of phytoplankton GALD for each sampling date to

276 investigate the size distribution dynamics over time in the two trophic levels. Additionally, we

277 performed a linear regression of mean phytoplankton GALD versus mean zooplankton size. All

278 analyses were performed using the statistical software $\mathrm{R}$ version 4.0.4 (R Core Team, 2021) with

279 the, magrittr, and vegan packages (Bach and Wickham, 2020; Oksanen et al., 2020). 


\section{RESULTS}

First, we assessed zooplankton and phytoplankton community composition and biomass during the summer growing season. Zooplankton biomass peaked $\left(249 \mu \mathrm{g} \mathrm{L}^{-1}\right)$ in late May and early June (DOY 150-164), rapidly decreased to its minimum $\left(\sim 2 \mu \mathrm{g} \mathrm{L}^{-1}\right)$ in mid-July to late August (DOY 192 - DOY 234), then returned to early summer concentrations through September (Figure 1A). The early summer zooplankton community was dominated by Daphnia and calanoid copepods which transitioned in early July (DOY 199) to a community dominated by Chydorus and cyclopoid copepods, then transitioning back to Daphnia in late August (Figure 1A). Zooplankton top-down control was very low $(<10 \%)$ over the course of the growing season with the percentage of zooplankton biomass to phytoplankton biomass peaking on DOY 164 at 6.9\%. Similar to zooplankton biomass, phytoplankton biomass was initially high in the spring, mainly composed of bacillariophytes, before rapidly decreasing during the clear-water period between DOY 150 - 164 when zooplankton biomass was at its highest (Figure 1B). Following DOY 172, the phytoplankton community was overwhelmingly composed of cyanophytes, mainly Microcystis, with phytoplankton reaching peak biomass on DOY $213\left(\sim 329 \mathrm{mg} \mathrm{L}^{-1}\right)$. The other dominant cyanophyte was the diazotroph Aphanothece, which was present from DOY $192-228$.

Nutrient concentrations and limitation were dynamic throughout the summer (Figure 2).

298 Inorganic $\mathrm{N}$ concentrations were highest in the spring and decreased by $80 \%$ to low or undetectable concentrations after DOY 178 (Figure 2A). At the same time, there was a rapid increase in inorganic P of 394\% from DOY 172 to 178 and a 937\% increase from DOY 178 to DOY 206 (Figure 2B). The storage of $\mathrm{N}$ in zooplankton biomass was negligible over the course of the growing season (Figure 2A), however $\mathrm{P}$ storage nearly equaled inorganic $\mathrm{P}$ concentrations in the water column early in the summer when zooplankton biomass peaked (Figure 2B). Total $\mathrm{N}: \mathrm{P}$ declined rapidly in mid-July (DOY 192), transitioning the ecosystem from P- to intermittent $\mathrm{N}$-limitation. There was also a shift in inorganic N:P to N-limitation in mid-July that was persistent for the remainder of the summer (Figure 2C). Zooplankton community body N:P was the highest in mid-summer, coincident with the rapid transition between $\mathrm{P}$ - and $\mathrm{N}$-limitation, then steadily declined throughout the rest of the sampling period (Figure 2D).

Supporting our hypothesis, zooplankton excretion contributed substantially to the inorganic P pool from late May to late June (DOY 143-172), with daily excretion ranging between 23-46\% of the inorganic P standing stock (Figure 3). Following DOY 172, the 
312 contribution of zooplankton excretion to the inorganic P pool dropped below $1 \%$ for the

313 remainder of the sampling period. Furthermore, zooplankton excretion was contributing to a

314 rapid turnover of the inorganic $\mathrm{P}$ pool in early summer with turnover times ranging between 3 -

3154 days but increased well beyond 365 days as inorganic P concentrations increased in late June

316 (Supplementary Table S4). Estimated zooplankton N excretion was never more than 3.3\% of the

317 inorganic N pool over the course of the growing season (Figure 3).

318 In support of our second hypothesis, the daily mass of zooplankton excretion

319 significantly explained variance in phytoplankton community composition during early summer

320 (DOY 143 - 164, Figure 4, Table 1). We found that the db-RDA discriminated the

321 phytoplankton community into distinct communities defined by pre- and post-cyanobacterial

322 dominance $(F=2.44, p=0.003)$. A suite of environmental variables explained $41.9 \%$ of the

323 variation in phytoplankton community composition including inorganic $\mathrm{P}(p=0.003)$ and $\mathrm{N}$

$324(p=0.020)$ concentrations, zooplankton $\mathrm{P}$ excretion $(p=0.004)$, temperature $(p=0.032)$, and total

325 dissolved solids ( $p=0.046$ ). Phytoplankton community composition was correlated with total

326 dissolved solids, zooplankton $\mathrm{N}$ and $\mathrm{P}$ excretion, and inorganic $\mathrm{N}$ concentrations in early

327 summer prior to the cyanobacteria bloom beginning on DOY 172 where phytoplankton

328 community composition became more correlated with inorganic $\mathrm{P}$ concentrations and

329 temperature. However, the significant axes did not explain a large proportion of the variation

330 with the first axis explaining $28.4 \%$ and the second axis explaining only $13.4 \%$ of variation.

331 Furthermore, there was evidence that zooplankton were influencing the size distribution

332 of phytoplankton GALD in mid- to late summer. There was a higher average GALD when mean

333 zooplankton length was at its lowest (Figure 5A), and the density of smaller zooplankton

334 individuals began increasing relative to the total size distribution in early June (DOY 164). Small

335 individual zooplankton dominated the zooplankton size distribution from late June to early

336 August (DOY 178 - 213). This was concurrent with a period in which larger phytoplankton

337 dominated the GALD distribution (Figure 5A). Phytoplankton average GALD was greatest in

338 July (mean $=32.5 \pm 19.6 \mu \mathrm{m}$; s.d.) concurrent with the period of the summer where zooplankton

339 average length was at its lowest (mean = $171 \pm 102 \mu \mathrm{m}$; s.d.). In late July through August the

340 difference in zooplankton length and phytoplankton GALD steadily increased, surpassing the

341 mean differences observed in early summer (Figure 5B). A similar pattern was observed between

342 phytoplankton GALD and zooplankton dry mass (Supplementary Figure S2). There was a weak 
343 negative relationship between GALD and zooplankton length $\left(p=0.0119, \mathrm{R}^{2}=0.42\right.$;

344 Supplementary Figure S3A), and zooplankton body mass $\left(p=0.0306, \mathrm{R}^{2}=0.33\right.$; Supplementary

345 Figure S3B).

\section{DISCUSSION}

\section{Effect of zooplankton excretion on nutrient availability}

349 We found that zooplankton excretion contributed substantially to the inorganic $\mathrm{P}$ pool in

350 Green Valley Lake, but only during the early summer (DOY 143 - 178). It was during this

351 period that inorganic $\mathrm{P}$ was at low concentrations in the water column and phytoplankton growth

352 was likely P-limited, indicating that zooplankton-mediated recycling contributed to meeting

353 nutrient demand by phytoplankton during this time. This early-season P availability, facilitated

354 by zooplankton recycling, may have helped initialize the cyanotoxin-producing cyanobacteria

355 bloom that flourished later in the season and persisted until late summer (Isles and Pomati,

356 2021). The large contribution of zooplankton to inorganic $P$ availability is consistent with the

357 hypothesis from Moody and Wilkinson (2019) that N-rich zooplankton communities,

358 characteristic of hypereutrophic lakes, contribute to increased $\mathrm{P}$ availability within nutrient-rich

359 ecosystems. Our study in Green Valley Lake, however, revealed that this zooplankton-mediated

360 flux of $\mathrm{P}$ is mainly confined to the early part of the growing season.

361 Beginning on DOY 178, the concentration of inorganic P in Green Valley Lake increased

362 substantially, diminishing the importance of zooplankton-recycled $\mathrm{P}$, and driving the ecosystem

363 to co-limitation or N-limitation for the rest of the season. The transition between $\mathrm{P}$ and N-

364 limitation or co-limitation is a dynamic that has been reported in other eutrophic and

365 hypereutrophic ecosystems (Andersen et al., 2020; Wang et al., 2019). The transition is likely a

366 result of increased internal P loading (Albright and Wilkinson, 2022) and differences in $\mathrm{N}$ uptake

367 strategies and preferences in the phytoplankton community, particularly when cyanobacteria

368 begin to dominate (Li et al., 2020; Glibert et al., 2016). Furthermore, our estimates of P turnover

369 by zooplankton indicated rapid turnover of inorganic pools during early summer, but drastically

370 slowed once inorganic $\mathrm{P}$ concentrations rose. These results support our conclusions that

371 zooplankton nutrient recycling was an important $\mathrm{P}$ flux during the early summer growing season,

372 but not an important flux once internal loading increased $\mathrm{P}$ availability. Additionally, it is

373 unlikely zooplankton had much influence over the turnover of total $\mathrm{P}$ and $\mathrm{N}$ across the entire 
374 summer, likely due to the lack of top-down control by the zooplankton community on

375 phytoplankton throughout the summer growing season.

Overall, the contribution of zooplankton-recycling to the inorganic $\mathrm{N}$ pool in Green Valley Lake was never greater than 5\%. However, the uptake of ammonium from zooplankton excretion by phytoplankton may have been too fast to result in a measurable concentration, masking the contribution of zooplankton excretion to $\mathrm{N}$ availability. Alternatively, we may be underestimating $\mathrm{N}$ excretion given that our estimates of zooplankton excretion were not taxonspecific but instead were based on a consolidated dataset of both cladocerans and copepods. This is particularly true when Cladocera dominate in the early and late-summer periods, which could increase community $\mathrm{N}$ excretion as Cladocera retain more $\mathrm{P}$ than $\mathrm{N}$ due largely to their body stoichiometry (Elser et al., 1988). Overall, our estimates of zooplankton excretion were low relative to the concentrations of inorganic nutrients in the ecosystem across the summer; however, they were comparable with other studies using similar allometric equations (Conroy et $a l ., 2005$ ) or direct measurement (den Oude and Gulati, 1988) in eutrophic ecosystems.

In addition to zooplankton, other consumers can play a key role in nutrient recycling in eutrophic ecosystems, particularly detritivores and planktivores such as gizzard shad (Sharitt et al., 2021; Vanni et al., 2006) and mussels (Arnott and Vanni, 1996). However, neither gizzard shad nor zebra mussels have been reported in Green Valley Lake. While we did not quantify the contribution of nutrient recycling by other consumers to availability in Green Valley Lake, these organisms certainly contributed. There is a common carp (Cyprinus carpio) population in Green

394 Valley Lake which can influence nutrient cycling through bioturbation and excretion (Weber and 395 Brown, 2009); however, the population is small. We hypothesize that the contributions of fish and other organisms would have a similar seasonality given the large contribution of internal $\mathrm{P}$ in the latter half of the season.

\section{Role of zooplankton excretion and grazing on phytoplankton community structure}

The redundancy analysis of phytoplankton community composition showed that the daily estimated rate of zooplankton $\mathrm{P}$ excretion was related to variation in phytoplankton community 402 composition prior to the cyanobacteria bloom later in summer. This suggests that zooplankton P 403 recycling, in part, influenced phytoplankton biomass and composition. The phytoplankton community was dominated by bacillariophytes and chlorophytes until DOY 172 when 
cyanophytes dominated the community. This transition is reflected in the discrimination of the phytoplankton community between pre- and post-cyanobacterial dominance in the redundancy analysis (db-RDA). The early summer phytoplankton community was also significantly related to the concentration of inorganic $\mathrm{N}$ and total dissolved solids. This corresponds with the seasonal dynamic of nutrient limitation as both chlorophytes and bacillariophytes perform well under Plimitation (Berg et al., 2003). Furthermore, the inorganic N pool was highest in early summer and predominantly composed of nitrate which can be taken up and used by bacillariophytes

412 (Andersen et al., 2020). The higher concentrations of total dissolved solids in the spring are 413 reflective of the input of ions from the watershed with spring melt, including nutrients such as 414 nitrate. These inputs combined with zooplankton excretion drove the community composition in 415 the spring.

Beginning on DOY 172, the phytoplankton community was overwhelmingly dominated

417 by Microcystis leading to very stable community composition during mid- and late summer. The 418 mid- to late-summer phytoplankton community was significantly related to temperature and 419 inorganic $\mathrm{P}$ concentrations, consistent with other studies describing increasing temperature and 420 N-limitation as key drivers of cyanobacteria dominance (Bogard et al., 2020; Hayes et al., 2020). 421 In fact, diazotrophic cyanobacteria (specifically, Aphanothece spp.) did not appear in the Green 422 Valley phytoplankton community until the onset of N-limitation. Other environmental factors 423 were likely influencing the phytoplankton community as the db-RDA described only $41.9 \%$ of 424 variation in the phytoplankton community composition. Phytoplankton community turnover is a 425 complex phenomenon driven by a multitude of environmental factors (Wentzky et al., 2020; 426 Sommer et al., 2012), including nutrient and light availability, the latter of which we did not 427 measure. Given the high biomass of phytoplankton, light limitation through self-shading likely 428 played a significant role in phytoplankton dynamics.

While we did not observe significant top-down control of zooplankton on phytoplankton 430 growth based on the Z:P ratios, we did find evidence that zooplankton may have influenced the 431 size structure of the phytoplankton community. The negative relationship between zooplankton 432 length and phytoplankton GALD is consistent with other studies in hypereutrophic lakes 433 indicating that small-bodied zooplankton preferentially graze on small-sized phytoplankton, 434 favoring growth of large filamentous and colonial phytoplankton (Bairagi et al., 2019; Onandia 435 et al., 2015). This is evidenced by the large bloom of Microcystis colonies midsummer that drove 
436 the increase in phytoplankton GALD we observed in July through early August. It is likely that 437 smaller-bodied zooplankton were contributing, in part, to the dominance of Microcystis colonies 438 and higher phytoplankton GALD. By grazing on smaller sized phytoplankton cells or colonies,

439 zooplankton can eliminate smaller phytoplankters leaving a greater proportion of individuals

440 with large GALD to dominate the overall size distribution. The size structure of communities is 441 closely tied to food web structure and energy flow (Brose et al., 2017), indicating that the 442 influence of zooplankton on phytoplankton size structure was influential for the transfer, uptake, 443 and recycling of nutrients by phytoplankton. However, it is unlikely zooplankton were the sole 444 cause of increased phytoplankton GALD as the drawdown of inorganic $\mathrm{N}$ we observed 445 midsummer coincided with the bloom of Microcystis beginning on DOY 172. Inorganic $\mathrm{N}$ is 446 known to promote Microcystis growth and was likely influencing the proliferation of Microcystis 447 colonies (Chen et al., 2019).

448 It is also likely that microzooplankton and ciliates played an important role grazing on 449 small phytoplankton species; however, we did not quantify these communities in this study.

450 Furthermore, our phytoplankton counting methods were unable to facilitate the identification of 451 nano- or picophytoplankton species in the water column. Microzooplankton, nano- and 452 picophytoplankton are increasingly recognized as key components of the plankton food web and 453 contribute a significant percentage of grazing pressure on phytoplankton in highly productive 454 ecosystems (Agasild et al., 2007; Zingel et al., 2007). Future studies should examine their 455 seasonal dynamics and potential contribution to ecosystem processes more thoroughly as they 456 can be key components of zooplankton-phytoplankton interactions in nutrient-rich lakes.

\section{CONCLUSIONS}

While the importance of consumer-driven nutrient recycling has been demonstrated in less eutrophic waterbodies, the role that zooplankton consumers play in nutrient availability and 461 phytoplankton dynamics in hypereutrophic lakes remained unclear. Our results support a 462 previous comparative study indicating that zooplankton community composition may influence 463 nutrient availability in hypereutrophic ecosystems, as well extend our understanding of the 464 temporal dynamics of zooplankton and phytoplankton interactions. We found evidence of the 465 importance of zooplankton nutrient cycling in a hypereutrophic reservoir with zooplankton excretion providing a large portion of the available $\mathrm{P}$ early in the summer, prior to the onset of 
467 the cyanobacteria-dominated bloom later in the season. Additionally, zooplankton influenced the 468 early summer phytoplankton community composition through excretion as well as phytoplankton 469 size structure, particularly later in the summer when cyanobacteria were blooming. As 470 demonstrated here, the role of zooplankton nutrient recycling in hypereutrophic lakes is an 471 important component of phytoplankton dynamics and ecosystem function that should be 472 considered in greater detail. Unlike previous assumptions that zooplankton do not contribute 473 substantially to nutrient cycling and phytoplankton dynamics, our results suggest that 474 zooplankton do in fact do contribute to those dynamics, predominantly for a short period early in 475 the summer. Future work should investigate the dynamics of zooplankton nutrient recycling 476 across different climate contexts and over longer time periods, including dynamics through 477 winter and autumn. 


\section{ACKNOWLEDGEMENTS}

479 We would like to thank Shania Walker, Halle Rosenboom, Quin Shingai, Rachel Fleck, Elena

480 Sandry, Psalm Amos, Julia Schneller, Adriana Le-Compte, and Ellen Albright for assistance with

481 sample collection and analysis. Additionally, we thank Riley Barbour for assistance with

482 phytoplankton identification and enumeration.

\section{FUNDING}

485 This project was funded by the Iowa Department of Natural Resources and the U.S. Department 486 of Agriculture National Institute of Food and Agriculture (Grant \# 2018-09746). This material is 487 based upon work supported by the National Science Foundation Graduate Research Fellowship 488 Program under Grant No. DGE-1747503. Any opinions, findings, and conclusions or recommendations expressed in this material are those of the authors and do not necessarily reflect the views of the National Science Foundation.

\section{DATA ARCHIVING}

493 The data for this study will be archived using the Environmental Data Initiative repository and

494 given a unique digital object identifier. Data will be uploaded in a comma delimited file format 495 with metadata composed of contact information, detailed variable descriptions, complete 496 taxonomic information, temporal resolution, and descriptions for a given variable when 497 appropriate. Metadata will follow the ecological metadata language and be published under a 498 creative commons license. Scripts for data analysis and figure generation will be available and 499 maintained online through GitHub (https://github.com/tjbutts/hyper-plankton) and will 500 eventually be published in Zenodo for long-term storage.

\section{REFERENCES}

503 Agasild, H. et al. (2007) Contribution of different zooplankton groups in grazing on phytoplankton in shallow eutrophic Lake Võrtsjärv (Estonia). Hydrobiologia, 584, 167177.

Ahmed, A. and Wanganeo, A. (2015) Phytoplankton succession in a tropical freshwater lake, Bhoj Wetland (Bhopal, India): spatial and temporal perspective. Environ. Monit. Assess., 187, 192. 
Albright, E. and Wilkinson, G. (2022) Sediment phosphorus composition controls hot spots and hot moments of internal loading in a temperate reservoir. EarthArxiv. Preprint.

Andersen, I. M. et al. (2020) Nitrate, ammonium, and phosphorus drive seasonal nutrient limitation of chlorophytes, cyanobacteria, and diatoms in a hyper-eutrophic reservoir. Limnol. Oceanogr., 65, 962-978.

Arnott, D. L. and Vanni, M. J. (1996) Nitrogen and phosphorus recycling by the zebra mussel (Dreissena polymorpha) in the western basin of Lake Erie. Can. J. Fish. Aquat. Sci., 53, 646-659.

Atkinson, C. L. et al. (2017) Consumer-driven nutrient dynamics in freshwater ecosystems: from

Bach, S. and Wickham, H. (2020) magrittr: A forward-Pipe Operator for R.

Bairagi, N. et al. (2019) Zooplankton selectivity and nutritional value of phytoplankton influences a rich variety of dynamics in a plankton population model. Phys. Rev. E, 99,

Balseiro, E. G. et al. (1997) Nutrient recycling and shifts in N:P ratio by different zooplankton structures in a South Andes Lake. J. Plankton Res., 19, 805-817.

Berg, G. M. et al. (2003) Plankton community composition in relation to availability and uptake of oxidized and reduced nitrogen. Aquat. Microb. Ecol., 30, 263-274.

Bogard, M. J. et al. (2020) Unabated Nitrogen Pollution Favors Growth of Toxic Cyanobacteria over Chlorophytes in Most Hypereutrophic Lakes. Environ. Sci. Technol., 54, 3219-3227.

Brose, U. et al. (2017) Predicting the consequences of species loss using size-structured biodiversity approaches. Biol. Rev., 92, 684-697.

Chen, Q. et al. (2019) Physiological effects of nitrate, ammonium, and urea on the growth and microcystins contamination of Microcystis aeruginosa: Implication for nitrogen mitigation. Water Res., 163, 114890.

Conroy, J. D. et al. (2005) Soluble nitrogen and phosphorus excretion of exotic freshwater mussels (Dreissena spp.): Potential impacts for nutrient remineralisation in western Lake Erie. Freshw. Biol., 50, 1146-1162.

Cottingham, K. L. et al. (2015) Cyanobacteria as biological drivers of lake nitrogen and phosphorus cycling. Ecosphere, 6, 1-19.

Dobberfuhl, D. R. and Elser, J. J. (2000) Elemental stoichiometry of lower food web components 
in arctic and temperate lakes. J. Plankton Res., 22, 1341-1354.

Dumont, H. J. et al. (1975) The dry weight estimate of biomass in a selection of Cladocera, Copepoda and Rotifera from the plankton, periphyton and benthos of continental waters. Oecologia, 19, 75-97.

Elser, J. and Hassett, R. (1994) A stoichiometric analysis of the zooplankton-phytoplankton interaction in marine and freshwater ecosystems. Nature, 370, 211-213.

Elser, J. J. et al. (2000) Pelagic C:N:P Stoichiometry in a Eutrophied Lake: Responses to a Whole-Lake Food-Web Manipulation. Ecosystems, 3, 293-307.

Elser, J. J. et al. (1988) Zooplankton-mediated transitions between N- and P-limited growth. Limnol. Oceanogr., 33, 1-14.

Elser, J. and Urabe, J. (1999) The Stoichiometry of Consumer-Driven Nutrient Recycling: Theory, Observations, and Consequences. Ecology, 80, 735-751.

Erdoğan, Ş. et al. (2021) Determinants of phytoplankton size structure in warm, shallow lakes. $J$. Plankton Res., 43, 353-366.

Filstrup, C. T. and Downing, J. A. (2017) Relationship of chlorophyll to phosphorus and nitrogen in nutrient-rich lakes. Inl. Waters, 7, 385-400.

Glibert, P. M. et al. (2016) Pluses and minuses of ammonium and nitrate uptake and assimilation by phytoplankton and implications for productivity and community composition, with emphasis on nitrogen-enriched conditions. Limnol. Oceanogr., 61, 165-197.

Guildford, S. J. and Hecky, R. E. (2000) Total nitrogen, total phosphorus, and nutrient limitation in lakes and oceans: Is there a common relationship? Limnol. Oceanogr., 45, 1213-1223.

Hamre, K. (2016) Nutrient profiles of rotifers (Brachionus sp.) and rotifer diets from four different marine fish hatcheries. Aquaculture, 450, 136-142.

Havens, K. E. and Beaver, J. R. (2013) Zooplankton to phytoplankton biomass ratios in shallow Florida lakes: An evaluation of seasonality and hypotheses about factors controlling variability. Hydrobiologia, 703, 177-187.

Hayes, N. M. et al. (2020) Effects of lake warming on the seasonal risk of toxic cyanobacteria exposure. Limnol. Oceanogr. Lett., 5, 393-402.

Hébert, M. P. et al. (2016a) A compilation of quantitative functional traits for marine and freshwater crustacean zooplankton. Ecology, 97, 1081.

Hébert, M. P. et al. (2016b) A meta-analysis of zooplankton functional traits influencing 
ecosystem function. Ecology, 97, 1069-1080.

Hébert, M. P. et al. (2017) Linking zooplankton communities to ecosystem functioning: Toward an effect-Trait framework. J. Plankton Res., 39, 3-12.

Hessen, D. O. et al. (2007) RNA responses to N- and P-limitation; reciprocal regulation of stoichiometry and growth rate in Brachionus. Funct. Ecol., 21, 956-962.

Hillebrand, H. et al. (1999) Biovolume calculation for pelagic and benthic microalgae. $J$. Phycol., 35, 403-424.

Isles, P. D. F. and Pomati, F. (2021) An operational framework for defining and forecasting phytoplankton blooms. Front. Ecol. Environ., in press.

Karpowicz, M. et al. (2020) Effect of eutrophication and humification on nutrient cycles and transfer efficiency of matter in freshwater food webs. Hydrobiologia, 847, 2521-2540.

Karpowicz, M. et al. (2021) Transfer efficiency of carbon, nutrients, and polyunsaturated fatty acids in planktonic food webs under different environmental conditions. Ecol. Evol., 1-14.

Legendre, P. and Anderson, M. (1999) Distance-based redundancy analysis: Testing multispecies responses in multifactorial ecological experiments. Ecol. Monogr., 69, 1-24.

Legendre, P. and Legendre, L. (1998) Numerical Ecology. 2nd ed. Elsevier, Amsterdam.

Leroux, S. and Loreau, M. (2015) Theoretical perspectives on bottom-up and top-down interactions across ecosystems. In Hanley, T. and La Pierre, K. (eds), Trophic Ecology: Bottom-up and top-down interactions across aquatic and terrestrial systems. Cambridge University Press, pp. 3-27.

Li, Y. et al. (2020) Evaluating the phytoplankton, nitrate, and ammonium interactions during summer bloom in tributary of a subtropical reservoir. J. Environ. Manage., 271, 110971.

Litchman, E. et al. (2013) Trait-based approaches to zooplankton communities. J. Plankton Res., 35, 473-484.

Matsuzaki, S. ichiro S. et al. (2018) Bottom-up linkages between primary production, zooplankton, and fish in a shallow, hypereutrophic lake. Ecology, 99, 2025-2036.

McCauley, E. (1984) The estimation of the abundance and biomass of zooplankton in samples. In Downing, J. and Rigler, F. (eds), A manual on methods for the assessment of secondary productivity in fresh waters. Blackwell Publishing Ltd, Oxford (UK), pp. 228-265.

Moegenburg, S. M. and Vanni, M. J. (1991) Nutrient regeneration by zooplankton: Effects on nutrient limitation of phytoplankton in a eutrophic lake. J. Plankton Res., 13, 573-588. 
602

Moody, E. K. and Wilkinson, G. M. (2019) Functional shifts in lake zooplankton communities with hypereutrophication. Freshw. Biol., 64, 608-616.

Moustaka-gouni, M. and Sommer, U. (2020) Effects of Harmful Blooms of Large-Sized and Colonial Cyanobacteria on Aquatic Food Webs. Water, 12, 1-19.

Oksanen, J. et al. (2020) vegan: Community Ecology Package.

Onandia, G. et al. (2015) Zooplankton grazing on natural algae and bacteria under hypertrophic conditions. Limnetica, 34, 541-560.

den Oude, P. J. and Gulati, R. D. (1988) Phosphorus and nitrogen excretion rates of zooplankton from the eutrophic Loosdrecht lakes, with notes on other P sources for phytoplankton requirements. Hydrobiologia, 169, 379-390.

Persson, J. et al. (2010) To be or not to be what you eat: Regulation of stoichiometric homeostasis among autotrophs and heterotrophs. Oikos, 119, 741-751.

Prater, C. et al. (2017) Interactive effects of genotype and food quality on consumer growth rate and elemental content. Ecology, 98, 1399-1408.

R Core Team (2021) R: A language and environment for statistical computing.

Rogers, T. et al. (2020) Trophic control changes with season and nutrient loading in lakes. Ecol. Lett., 23, 1287-1297.

Rönicke, H. et al. (2010) Changes of the plankton community composition during chemical neutralisation of the Bockwitz pit lake. Limnologica, 40, 191-198.

Sarnelle, O. and Knapp, R. A. (2005) Nutrient recycling by fish versus zooplankton grazing as drivers of the trophic cascade in alpine lakes. Limnol. Oceanogr., 50, 2032-2042.

Sharitt, C. A. et al. (2021) Nutrient excretion by fish supports a variable but significant proportion of lake primary productivity over 15 years. Ecology, 0, 1-8.

Sommer, U. et al. (2012) Beyond the Plankton Ecology Group (PEG) Model: Mechanisms Driving Plankton Succession. Annu. Rev. Ecol. Evol. Syst., 43, 429-448.

Song, K. and Burgin, A. J. (2017) Perpetual Phosphorus Cycling: Eutrophication Amplifies Biological Control on Internal Phosphorus Loading in Agricultural Reservoirs. Ecosystems, 20, 1483-1493.

Sournia, A. (1978) Phytoplankton Manual. Monographs on Oceanographic Methodology. UNESCO, Paris.

Spooner, D. E. et al. (2013) Nutrient loading associated with agriculture land use dampens the 

importance of consumer-mediated niche construction. Ecol. Lett., 16, 1115-1125.

Sterner, R. W. (1990) The Ratio of Nitrogen to Phosphorus Resupplied by Herbivores : Zooplankton and the Algal Competitive Arena. Am. Nat., 136, 209-229.

Sterner, R. W. and Elser, J. J. (2002) Ecological Stoichiometry: The Biology of Elements from Molecules to the Biosphere.

Stoddard, J. L. et al. (2016) Continental-Scale Increase in Lake and Stream Phosphorus: Are Oligotrophic Systems Disappearing in the United States? Environ. Sci. Technol., 50, 34093415.

Striebel, M. et al. (2016) Phytoplankton responses to temperature increases are constrained by abiotic conditions and community composition. Oecologia, 182, 815-827.

Teurlincx, S. et al. (2017) Species sorting and stoichiometric plasticity control community C:P ratio of first-order aquatic consumers. Ecol. Lett., 20, 751-760.

Vanni, M. J. (2002) Nutrient cycling by animals in freshwater ecosystems. Annu. Rev. Ecol. Syst., 33, 341-370.

Vanni, M. J. et al. (2006) Nutrient cycling by fish supports relatively more primary production as lake productivity increases. Ecology, 87, 1696-1709.

Wang, M. et al. (2019) Seasonal Pattern of Nutrient Limitation in a Eutrophic Lake and Quantitative Analysis of the Impacts from Internal Nutrient Cycling. Environ. Sci. Technol.,

652 Weber, M. J. and Brown, M. L. (2009) Effects of Common Carp on Aquatic Ecosystems 80 Years after "Carp as a Dominant": Ecological Insights for Fisheries Management. Rev. Fish. Sci., 17, 524-537.

Wentzky, V. C. et al. (2020) Seasonal succession of functional traits in phytoplankton communities and their interaction with trophic state. J. Ecol., 108, 1649-1663. naturally highly eutrophic lake. Microb. Ecol., 53, 134-142. 
TABLE \& FIGURE LEGENDS

661 Table 1. Statistics for the distance based-Redundancy Analysis (db-RDA) of phytoplankton

662 community composition in Green Valley Lake from May to September 2019.

664 Figure 1. (A) Zooplankton biomass and community composition and (B) phytoplankton biomass and community composition over the course of the growing season in Green Valley Lake, IA.

Figure 2. (A) Surface water nitrogen and (B) phosphorus concentrations split between total, inorganic, and zooplankton body storage over the course of the growing season. Additionally,

(C) surface water molar nitrogen: phosphorus (N:P) ratios split between total and inorganic pools as well as (D) molar N:P ratios of the zooplankton community.

Figure 3. The estimated concentration of total zooplankton community excretion produced over a day compared with the surface water inorganic phosphorus and nitrogen concentrations measured the same day as a percentage. Estimates of zooplankton excretion were derived from published allometric equations of zooplankton body size and excretion rate (Hébert, et al., 2016). The dark lines represent the estimated excretion of either phosphorus or nitrogen, and the shaded area represents the error associated with the estimate for each sampling day.

Figure 4. Distance based-Redundancy Analysis (db-RDA) of the phytoplankton community in 680 Green Valley Lake from May to September 2019. Dots represent sampling points, and the numbers 1-14 are DOY 143, 150, 164, 172, 178, 192, 199, 206, 211, 213, 220, 227, 245, 251, respectively. DOY 245 (13) was omitted from the diagram as there were no available data for 683 inorganic $\mathrm{N}$ and $\mathrm{P}$ thus the data were omitted from the analysis. The explanatory variables are represented by arrows with significance denoted by an asterisk.

686 Figure 5. (A) Density ridgeline plots of phytoplankton greatest axial distance (GALD, $\mu \mathrm{m})$ and zooplankton body size $(\mu \mathrm{m})$ over the course of the growing season in Green Valley Lake, IA.

688 The black vertical line within each distribution represents the mean. (B) Mean difference 689 between zooplankton length and phytoplankton GALD. DOYs that are missing either phytoplankton GALD or zooplankton length are the result of sample loss or no available data. 


\section{TABLES}

692 Table 1.

\begin{tabular}{r|ccc}
\multicolumn{1}{r}{ Permutation test variable } & Sums of & pseudo- & $\boldsymbol{p}$ - \\
vquares & $\boldsymbol{F}$ & value \\
\hline Full model & 2.58 & 2.44 & $\mathbf{0 . 0 0 3}$ \\
Second axis & 0.49 & 2.76 & $\mathbf{0 . 0 3 0}$ \\
Inorganic P & 0.54 & 3.07 & $\mathbf{0 . 0 0 3}$ \\
Inorganic N & 0.41 & 2.32 & $\mathbf{0 . 0 2 0}$ \\
Zooplankton P excretion & 0.58 & 3.27 & $\mathbf{0 . 0 0 4}$ \\
Zooplankton N excretion & 0.28 & 1.59 & 0.099 \\
Temperature $\left({ }^{\circ} \mathrm{C}\right)$ & 0.37 & 2.12 & $\mathbf{0 . 0 3 2}$ \\
Total Dissolved Solids & 0.40 & 2.28 & $\mathbf{0 . 0 4 6}$ \\
Residual & 1.06 & &
\end{tabular}



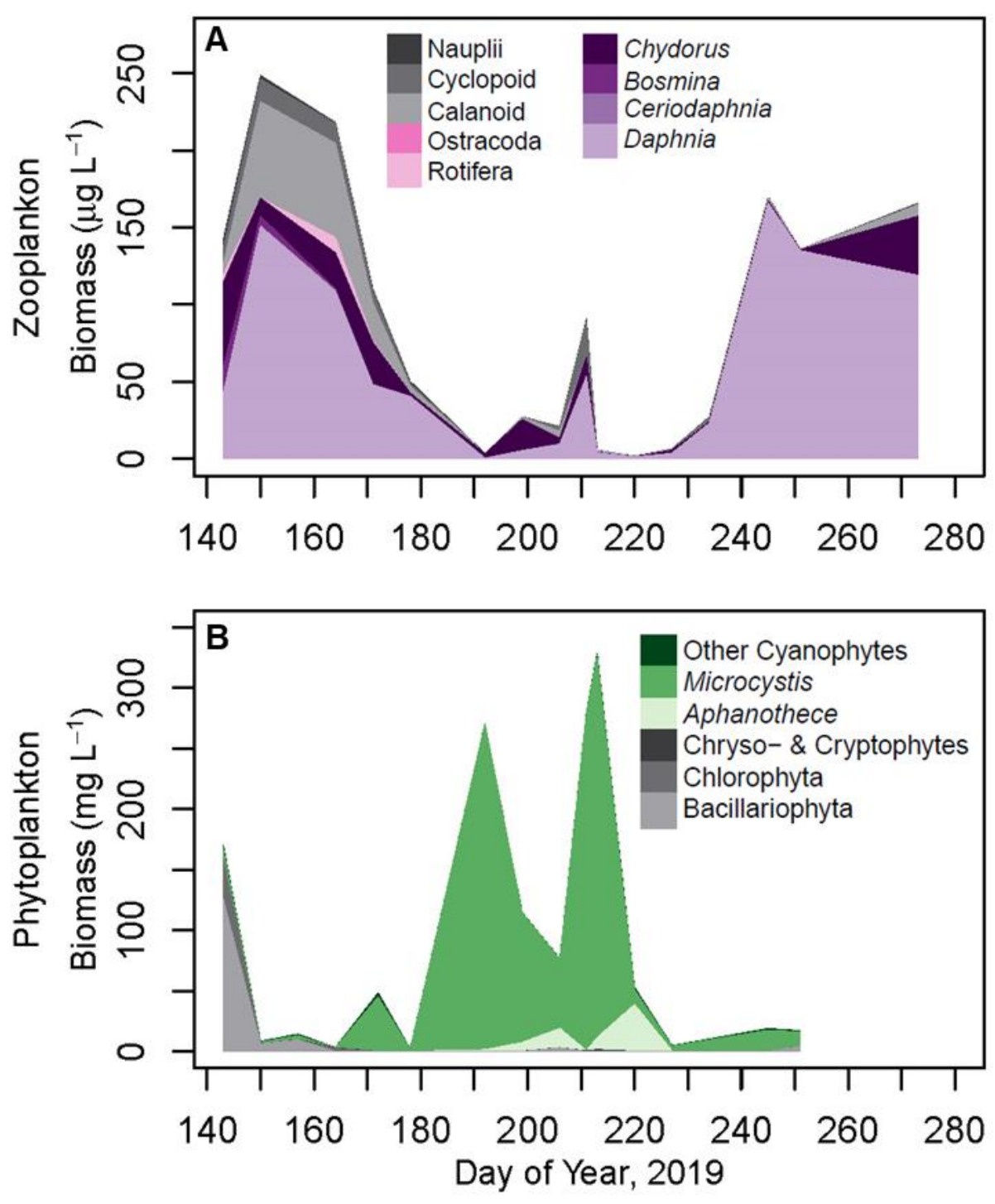

694

695 Figure 1. 

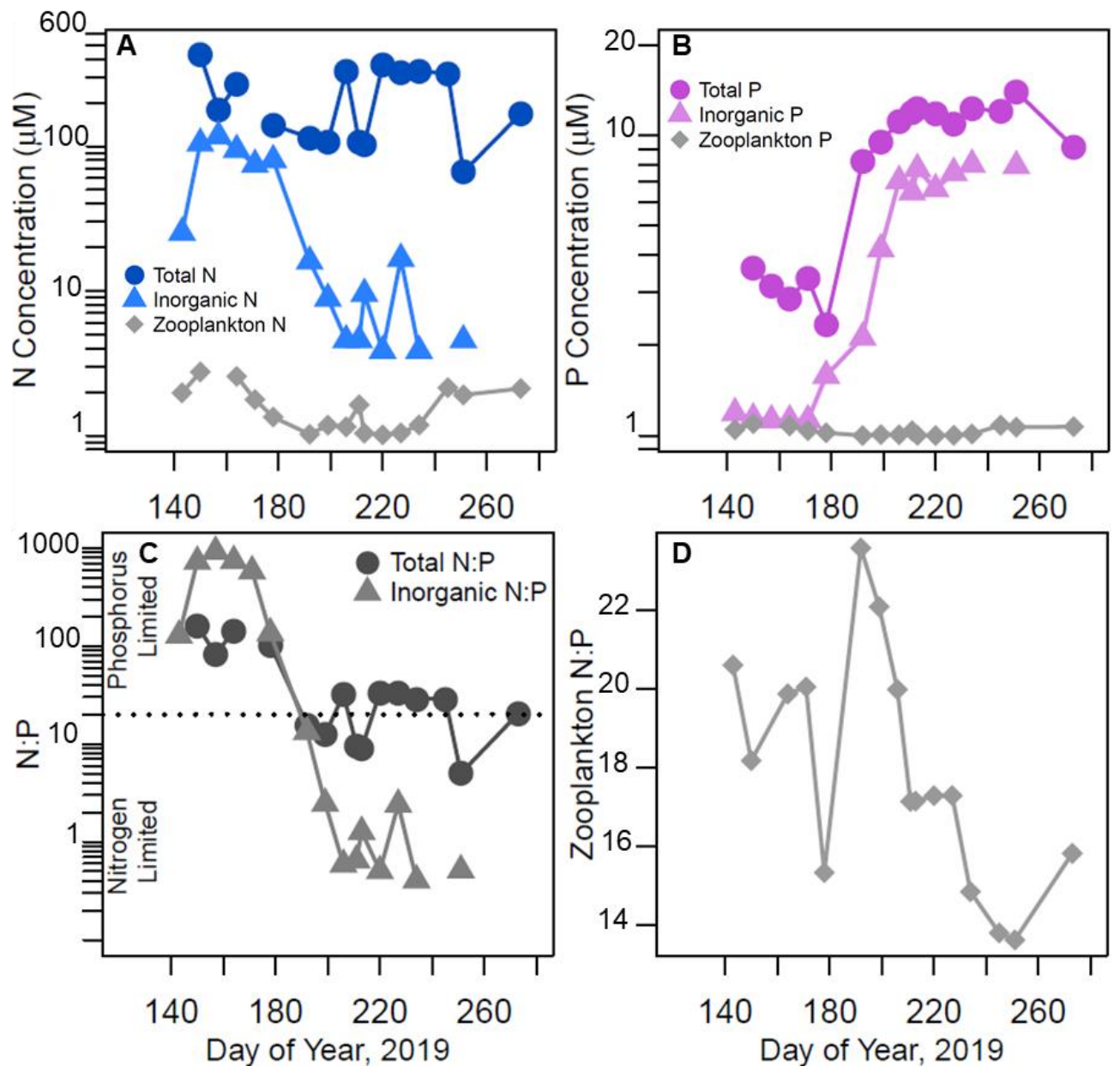

697 Figure 2. 


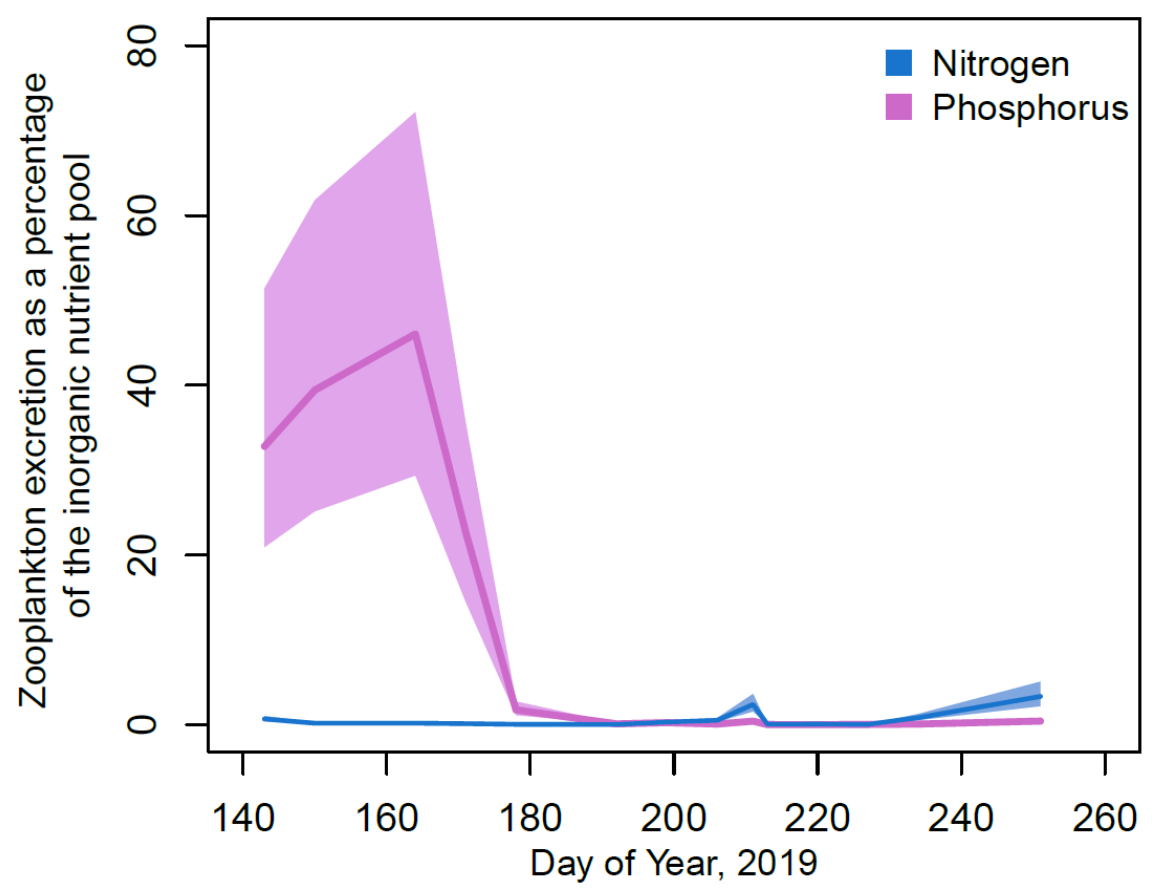

699 Figure 3. 


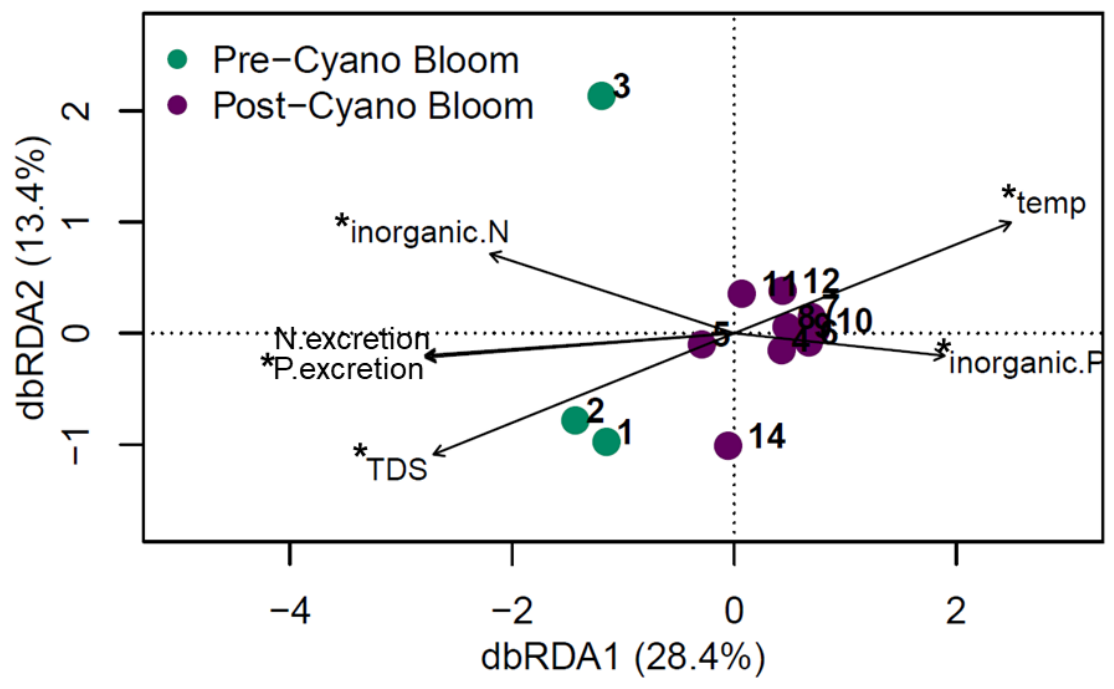

700

701 Figure 4. 
Phytoplankton GALD $\square$ Zooplankton Length

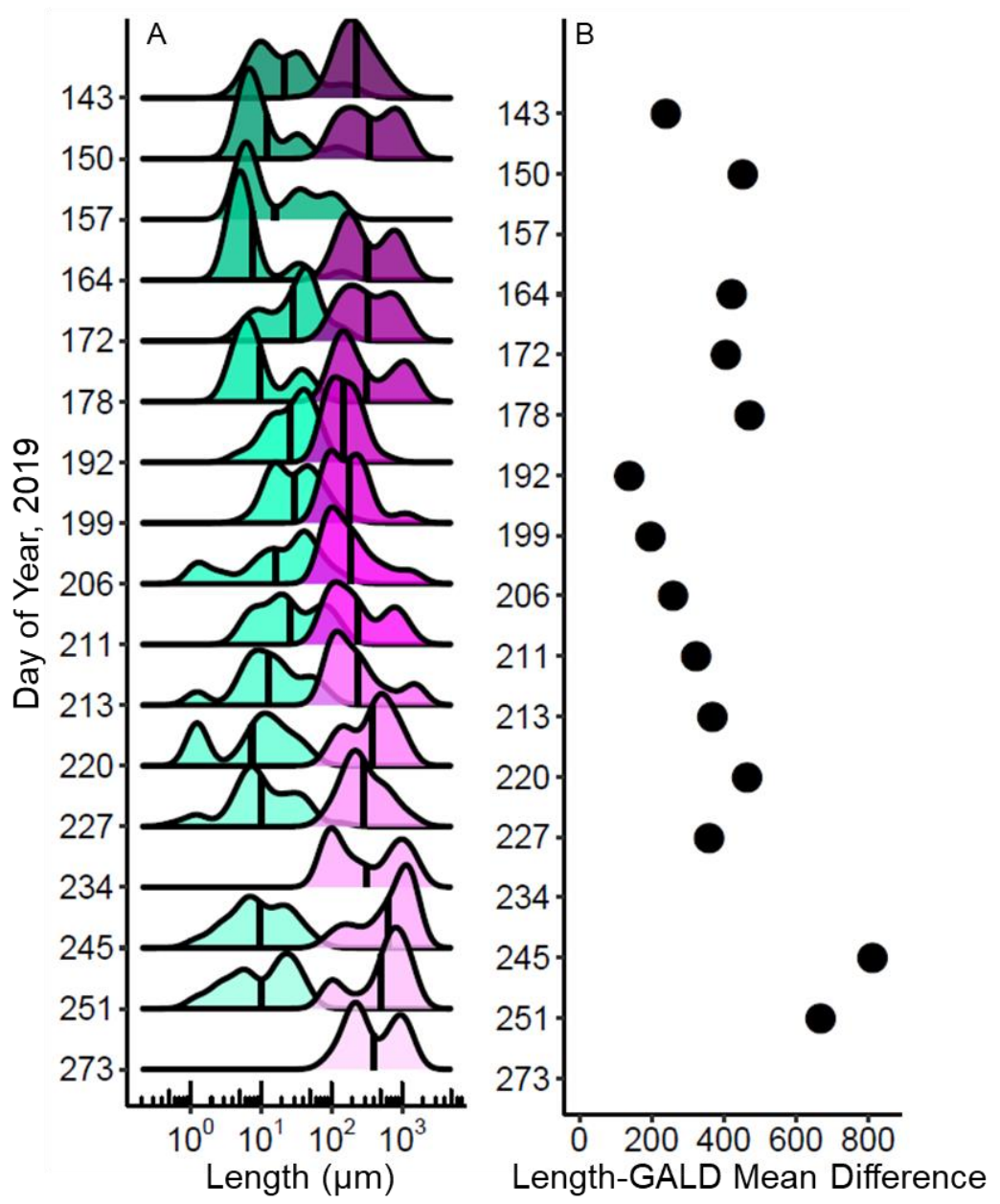

704

705 Figure 5. 


\section{Supplementary Material}

allowing calculation of $\operatorname{org} N$ by rearranging (2):

$$
\operatorname{org} N=T N-N O x
$$

717 Thus, we could characterize $\mathrm{N}$ pools as total $(T N)$ representing dissolved and particulate forms of $718 \mathrm{~N}$, organic $(\operatorname{org} N)$ representing dissolved organic $\mathrm{N}$ (urea) and seston, and inorganic $\mathrm{N}(N O x)$ 719 representing DIN in the surface waters. For our analyses we focused on the TN and DIN pools.

Similarly, $\mathrm{P}$ is composed of organic and inorganic fractions in reservoir surface waters:

$$
T P=P O P+P I P+D I P+D O P
$$

721 where $T P$ is total $\mathrm{P}, P O P$ is particulate organic $\mathrm{P}, P I P$ is particulate inorganic $\mathrm{P}, D I P$ is dissolved 722 inorganic $\mathrm{P}$, and $D O P$ is dissolved organic P. DIP and PIP were both present within the water 723 column, but our focus for this study was on DIP which is far more bioavailable to phytoplankton 724 than PIP (Zhou et al., 2005) and thus more influential to nutrient cycling via zooplankton-

725 phytoplankton interactions. Previous data from the last decade in Green Valley Lake indicated 726 PIP was extremely low or undetectable in the surface waters during the summer months. Thus, 727 (4) can be simplified by combining $D O P$ and $P O P$ to one organic pool ( $\operatorname{rg} P$ ) and using $S R P$ as 728 a measure of $D I P$ over the course of the growing season:

$$
T P=\operatorname{org} P+S R P
$$


729 Therefore, we could characterize P pools as total $(T P)$ representing dissolved and particulate

730 forms of $\mathrm{P}$, organic $(\operatorname{org} P)$ representing dissolved organic $\mathrm{P}$ and seston, and inorganic $(S R P)$

731 representing DIP in the surface waters. For our analyses we focused on the TP and SRP pools.

732 Ammonium + ammonia (NHx) (EPA method 103-A v6) and inorganic suspended solids

733 were measured at the same location in the lake three times during the summer by the Iowa

734 Ambient Lakes Monitoring program (IDNR 2021). Ammonium was analyzed through the

735 alkaline phenate method on a Seal Analytical AQ2 Discrete Analyzer and inorganic particulates

736 were determined via difference between total and volatile suspended solids (USGS method I-

737 3765-85).

738

739

\section{Zooplankton excretion equations}

740 Individual zooplankton excretion of $\mathrm{P}$ was determined using the following equation from Hébert 741 et al., (2016):

$$
\ln \left(P_{e x c, h}\right)=2.50+\left(0.84 \ln \left(Z_{B S}\right)\right)
$$

742 where $P_{\text {exc, }}$ is excreted $\mathrm{P}\left(\mathrm{nM}\right.$ of $\mathrm{P}$ individual ${ }^{-1}$ hour $\left.^{-1}\right)$ and $Z_{B S}$ is the dry mass of an individual

743 zooplankter (mg). Zooplankton excretion of $\mathrm{N}$ was determined in a similar manner:

$$
\ln \left(P_{\text {exc, }}\right)=0.56+\left(0.70 \ln \left(Z_{B S}\right)\right)
$$

744 where $N_{\text {exc }, h}$ is excreted $\mathrm{N}\left(\mathrm{nM}\right.$ of $\mathrm{N}$ individual ${ }^{-1}$ hour $\left.^{-1}\right)$.

745 Data were then converted to $\mu \mathrm{M}$ of $\mathrm{N}$ or $\mathrm{P}$ per day using the following conversions:

$$
\frac{\text { nmol } N \text { or } P}{\text { individual } \cdot \text { hour }} \cdot \frac{24 \text { hours }}{1 \text { day }} \cdot \frac{\text { individuals }}{L} \cdot \frac{1 \mu \mathrm{mol}}{1000 \mathrm{nmol}}=\frac{\mu M N \text { or } P}{\text { day }}
$$

The allometric equations were derived from a combined dataset of marine and freshwater

747 zooplankton. Using only the freshwater data did not significantly change the slope, nor was the

748 relationship between excretion and body size significant due to the much smaller sample size.

749 Thus, we only present the combined freshwater and marine model as presented in Hébert et al.

750 (2016). Additionally, we used zooplankton excretion equations from Wen and Peters (1994).

751 Specifically, we used their multivariate regression equations for crustacean zooplankton which

752 corrected for temperature $(\mathrm{K})$ and experimental duration $(\mathrm{h})$ in their estimates of excretion. As 
753 our data did not have an experimental duration, we dropped the experimental duration correction 754 resulting in the following equations:

$$
\log _{10}\left(P_{\text {exc }, w p}\right)=-5.28+\left(0.61 * \log _{10}\left(Z_{B S}\right)\right)+(0.01 * T)
$$

755 Where $P_{\text {exc,wp }}$ is excreted $\mathrm{P}\left(\mu \mathrm{g} \mathrm{d}^{-1}\right), Z_{B S}$ is the body size of an individual zooplankter $(\mu \mathrm{g})$, and $T$ 756 is water temperature (K).Similarly, for N excretion:

$$
\log _{10}\left(N_{\text {exc,wp }}\right)=-3.47+\left(0.74 * \log _{10}\left(Z_{B S}\right)\right)+\left(0.00002 * T^{2}\right)
$$

757 Where $N_{\text {exc,wp }}$ is excreted $\mathrm{N}\left(\mu \mathrm{g} \mathrm{d}^{-1}\right), Z_{B S}$ is the body size of an individual zooplankter $(\mu \mathrm{g})$, and $T$ 758 is water temperature $(\mathrm{K})$. The pattern of zooplankton excretion was consistent between the two 759 methods; however, the magnitude of excretion was different (Supplementary Table S3).

\section{SUPPLEMENTARY REFERENCES}

762 Hébert, M. P. et al. (2016) A meta-analysis of zooplankton functional traits influencing 763 ecosystem function. Ecology, 97, 1069-1080.

764 Iowa Department of Natural Resources (IDNR) (2021) Water Quality Monitoring and 765 Assessment Section. AQuIA [database].

766 Wen, Y. H. and Peters, R. H. (1994) Empirical models of phosphorus and nitrogen excretion 767 rates by zooplankton. Limnol. Oceanogr., 39, 1669-1679.

768 Zhou, A. et al. (2005) Phosphorus adsorption on natural sediments: Modeling and effects of $\mathrm{pH}$ 769 and sediment composition. Water Res., 39, 1245-1254. 
771 Tables

772 Table S1. Zooplankton genera, order, or class identified over the course of the growing season in

773 Green Valley Lake.

Taxonomic Group Taxa identified in Green Valley Lake included in grouping

\begin{tabular}{ll}
\hline Large Cladocera & Daphnia \\
& Simnocephalus \\
& Ceriodaphnia \\
\hline Small Cladocera & Bosmina \\
& Chydorus \\
\hline Ostracod & Ostracoda \\
\hline Calanoids & Calanoida \\
\hline Cyclopoids & Cyclopoida \\
\hline Nauplii & Copepod nauplii \\
\hline Rotifers & Asplanchna \\
& Keratella cochlearis \\
& Keratella quadrata \\
& Pompholyx \\
& Trichocerca \\
& Filinia
\end{tabular}

774 
775 Table S2. Phytoplankton genera identified over the course of the growing season in Green

776 Valley Lake.

Taxonomic Group Taxa identified in Green Valley Lake included in grouping

\begin{tabular}{|c|c|}
\hline \multirow[t]{5}{*}{ Bacillariophyta } & Asterionella \\
\hline & Fragilaria \\
\hline & Stephanodiscus \\
\hline & Unknown pennate bacillariophyte \\
\hline & Unknown centric bacillariophyte \\
\hline \multirow[t]{12}{*}{ Chlorophyta } & Chalmydomonas \\
\hline & Coelastrum \\
\hline & Cosmarium \\
\hline & Desmodesmus \\
\hline & Elakatothrix \\
\hline & Eudorina \\
\hline & Monoraphidium \\
\hline & Oocystis \\
\hline & Pediastrum \\
\hline & Schroederia \\
\hline & Staurastrum \\
\hline & Unknown chlorophyte \\
\hline \multirow{3}{*}{$\begin{array}{l}\text { Chyrso - \& } \\
\text { Cryptophytes }\end{array}$} & Mallomonas \\
\hline & Cryptomonas \\
\hline & Komma \\
\hline $\begin{array}{l}\text { Aphanothece } \\
\text { (Cyanophyte) }\end{array}$ & Aphanothece \\
\hline Microcystis & Microcystis \\
\hline (Cyanophyte) & Microcystis (Single-celled) \\
\hline \multirow[t]{3}{*}{ Other Cyanophytes } & Aphanizomenon \\
\hline & Aphanocapsa \\
\hline & Merismopedia \\
\hline
\end{tabular}




\begin{tabular}{l}
\hline Planktolyngbya \\
\hline Pseudanabaena \\
\hline Snowella \\
\hline Woronichinia \\
\hline Dolichospermum
\end{tabular}


778 Table S3. Estimated zooplankton excretion of $\mathrm{N}$ and $\mathrm{P}\left(\mu \mathrm{M} \mathrm{d}^{-1}\right)$ using different published 779 allometric equations from Hébert et al. (2016) and Wen and Peters (1994). Uncertainty estimates

780 derived from the allometric equation parameters in Hébert et al. (2016) are presented in 781 parentheses.

Zooplankton Excretion ( $\mu \mathrm{M} \mathrm{N}$ or $\mathrm{P}$ day $^{-1}$ )

\begin{tabular}{c|cc|cc}
\multicolumn{1}{c}{ Nitrogen Excretion } & \multicolumn{2}{c}{ Phosphorus Excretion } \\
\cline { 2 - 6 } DOY & Hébert & Wen \& Peters & Hébert & Wen \& Peters \\
143 & $0.159(0.143-0.242)$ & 0.073 & $0.062(0.040-0.100)$ & 0.080 \\
150 & $0.177(0.116-0.270)$ & 0.082 & $0.056(0.036-0.088)$ & 0.072 \\
164 & $0.167(0.110-0.255)$ & 0.083 & $0.058(0.037-0.091)$ & 0.081 \\
171 & $0.087(0.057-0.133)$ & 0.039 & $0.029(0.018-0.045)$ & 0.036 \\
178 & $0.034(0.022-0.051)$ & 0.014 & $0.010(0.007-0.016)$ & 0.012 \\
192 & $0.003(0.002-0.004)$ & 0.002 & $0.001(0.001-0.002)$ & 0.002 \\
199 & $0.022(0.014-0.033)$ & 0.012 & $0.008(0.005-0.012)$ & 0.011 \\
206 & $0.015(0.010-0.022)$ & 0.007 & $0.005(0.003-0.007)$ & 0.006 \\
211 & $0.068(0.045-0.104)$ & 0.035 & $0.023(0.014-0.035)$ & 0.032 \\
213 & $0.004(0.002-0.005)$ & 0.002 & $0.001(0.001-0.007)$ & 0.001 \\
220 & $0.001(0.001-0.002)$ & 0.001 & $0.000(0.000-0.002)$ & 0.001 \\
227 & $0.005(0.003-0.007)$ & 0.002 & $0.002(0.001-0.003)$ & 0.002 \\
234 & $0.018(0.012-0.027)$ & 0.008 & $0.005(0.003-0.008)$ & 0.007 \\
245 & $0.109(0.072-0.167)$ & 0.046 & $0.031(0.020-0.049)$ & 0.037 \\
251 & $0.095(0.062-0.145)$ & 0.042 & $0.029(0.019-0.046)$ & 0.036 \\
273 & $0.120(0.079-0.183)$ & 0.051 & $0.039(0.025-0.061)$ & 0.046 \\
& & & &
\end{tabular}

782

783 
784 Table S4. Potential zooplankton nutrient turnover of various nutrient pools in Green Valley Lake 785 representing the number of days it would take zooplankton excretion alone to meet the water

786 column concentration of total phosphorus, total nitrogen, or inorganic phosphorus on a given

787 sampling day. Missing values were the result of sample loss or the lack of available data and are 788 denoted by NA.

\begin{tabular}{l|cccccc} 
& DOY & DOY & DOY & DOY & DOY & DOY \\
Nutrient Pool & 143 & 150 & 164 & 172 & 178 & $192-273$ \\
\hline Soluble Phosphorus & 3 & 3 & 2 & 4 & 57.3 & $>365$
\end{tabular}

789 

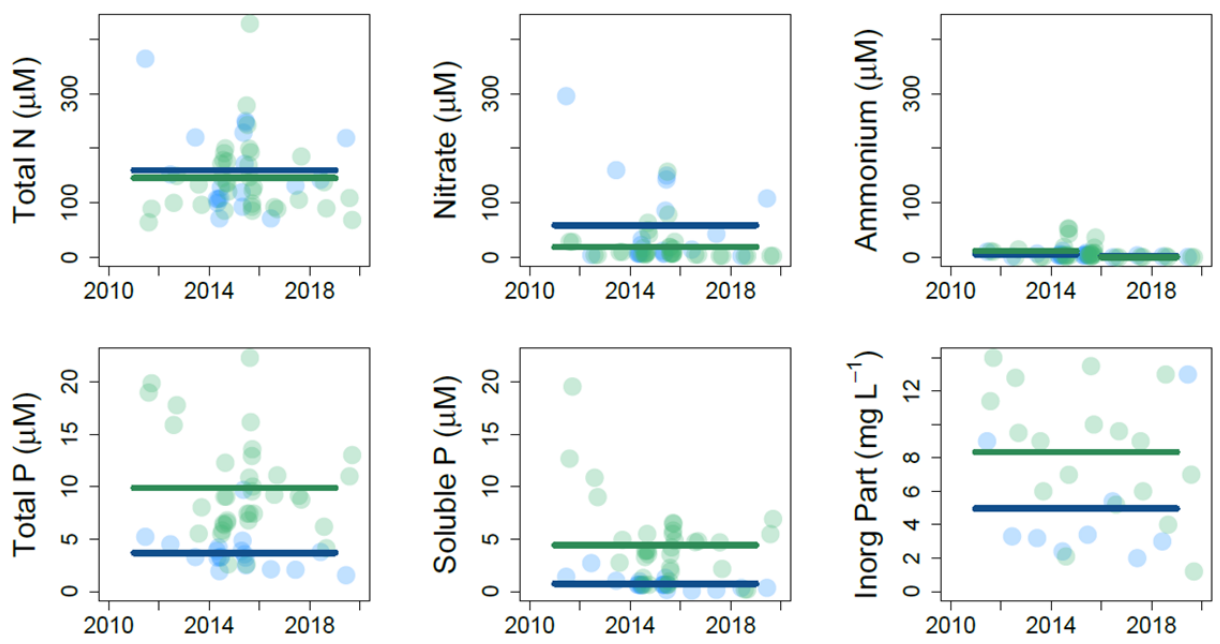

DOY $<170$
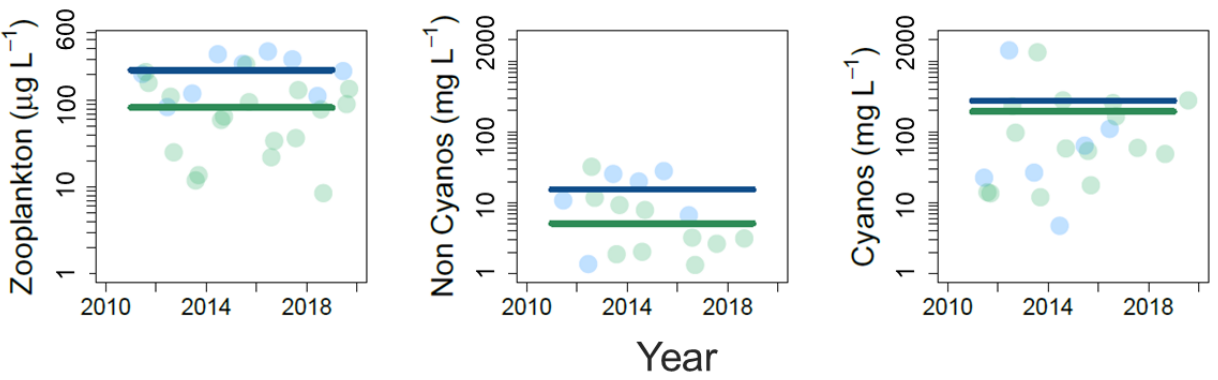

791

792 Figure S1. Historical water quality and plankton data for Green Valley Lake. The solid

793 horizontal line is the mean value for the period $2011-2019$ split between before or after the

794 clear-water period which we determined was around DOY 170 using a breakpoint analysis. From

795 left to right, top to bottom the variables represented are total nitrogen, nitrate, ammonium, total

796 phosphorus, soluble reactive phosphorus, inorganic particulates, zooplankton biomass, non-

797 Cyanophyta biomass, and Cyanophyta biomass. Data were collated from the Ambient Lakes

798 Monitoring program in the state of Iowa (IDNR, 2021). Ammonium concentrations became 799 extremely low or undetectable past 2015 and thus the mean value was split between pre- and 800 post-2015.

801 

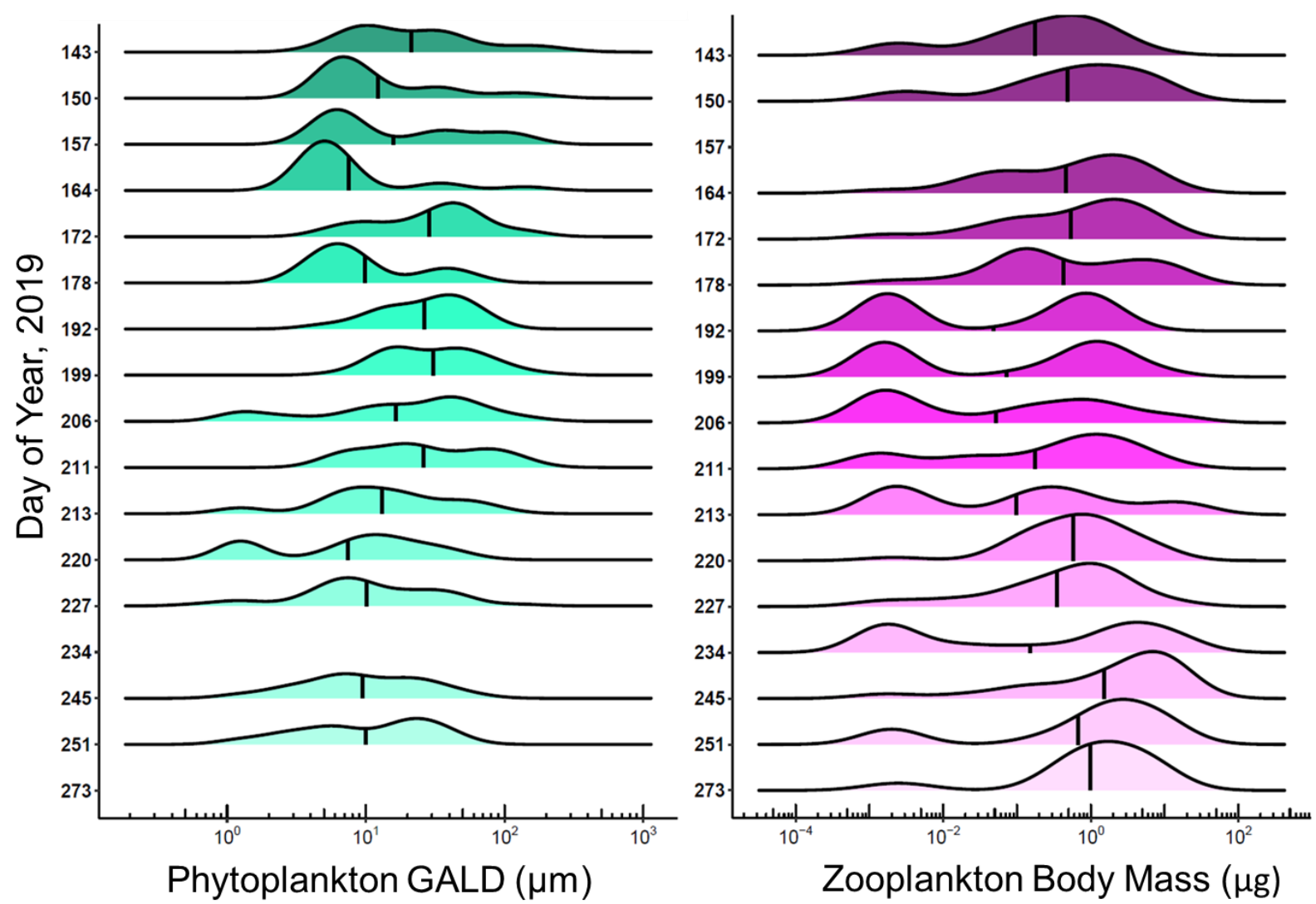

803 Figure S2. Density ridgeline plots of phytoplankton greatest axial distance (GALD, $\mu \mathrm{m})$ and 804 zooplankton body mass $(\mu \mathrm{g})$ over the course of the growing season in Green Valley Lake, IA.

805 The black vertical line within each distribution represents the mean. DOYs that are missing 806 either phytoplankton GALD or zooplankton length are the result of sample loss or no available 807 data. 

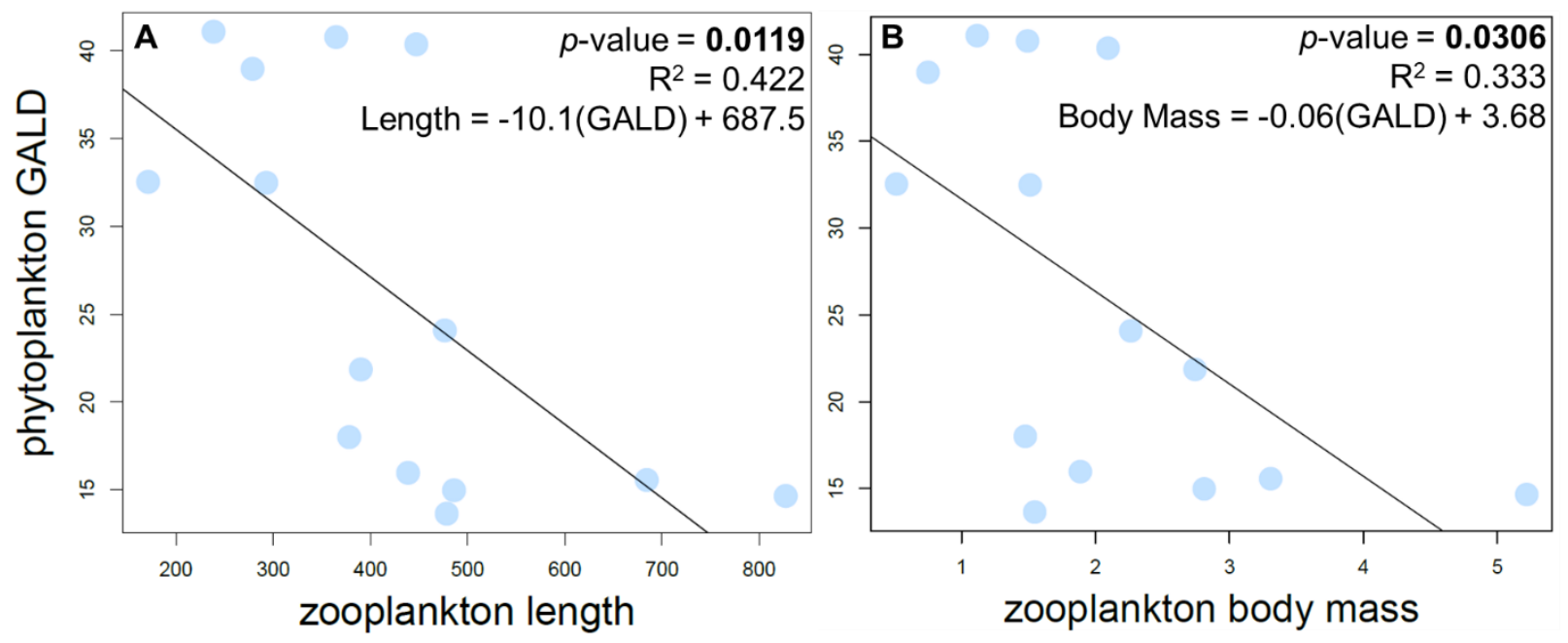

808

809 Figure S3. Linear regression of (A) zooplankton body length $(\mu \mathrm{m})$ and (B) zooplankton body

810 mass $(\mu \mathrm{g})$ by phytoplankton greatest axial linear distance (GALD, $\mu \mathrm{m})$. 